\title{
SUCINTA INTRODUÇÃO AO CONCEITO DE DESENVOLVIMENTO ECONÔMICO NA PERSPECTIVA DE BRESSER-PEREIRA
}

\author{
Osmar Faustino Oliveira ${ }^{1}$ \\ Manoel Raymundo de Carvalho Neto ${ }^{2}$ \\ Flávio Antônio Miranda de Souza ${ }^{3}$
}

\section{RESUMO:}

O artigo faz uma breve e sucinta introdução ao conceito de desenvolvimento sob a ótica de Bresser-Pereira. Analisa sucintamente o que a literatura bresserniana discute sobre desenvolvimento econômico. Desenvolvimento enquanto conceito é de extrema importância para ciências econômicas e sociais e se constitui em campo de luta entre os autores em busca de uma definição mais precisa do conceito. Nesse trabalho sintetiza-se a concepção do Bresser-Pereira a luz de outros autores também considerados desenvolvimentistas.

Palavras-Chave: Desenvolvimento Econômico. Bresser-Pereira. Economia.

\section{ABSTRACT:}

The article makes a brief and succinct introduction to the concept of development from Bresser-Pereira's point of view. It briefly analyzes what the bressernian literature discusses about economic development. Development as a concept is of extreme importance for economic and social sciences and is a field of struggle between authors in search of a more precise definition of the concept. In this work the Bresser-Pereira conception is synthesized in light of other authors also considered developmentalists

Keywords: Economic Development. Bresser-Pereira. Economy.

\section{INTRODUÇÃO}

O conceito de desenvolvimento econômico é bastante amplo e precisa ser mais debatido no meio acadêmico. Na visão de Bresser-Pereira (2006), desenvolvimento econômico é um fenômeno histórico que ocorre nos países ou estados-nação que realizam sua revolução capitalista, caracterizados pelo aumento

1 Mestrando na Universidade Federal de Pernambuco. osmarfaustino25@gmail.com

2 Mestre em Gestão e Economia da Saúde. Universidade Federal de Pernambuco. E-mail: anoelneto.ufpe@gmail.com

3 Doutorado em Planejamento Urbano - Oxford Brookes University - fdesouza67@gmail.com 
apoiado da produtividade ou da renda por habitante, seguido por um metódico processo de acumulação de capital e incorporação de progresso técnico.

O presente trabalho tem como objetivo ilustrar por meio de uma discussão teórica, os conceitos de desenvolvimento econômico, tomando como base o artigo de Bresser-Pereira sobre o conceito histórico de desenvolvimento econômico. A pesquisa realizou uma investigação bibliográfica, que por meio de uma discussão teórica sobre o que é desenvolvimento econômico.

\section{O CONCEITO DE DESENVOLVIMENTO EM BRESSER-PEREIRA}

A ideia de desenvolvimento sempre esteve presente nas diferentes concepções dos estudiosos das ciências econômicas, entretanto, a Teoria do Desenvolvimento originou-se, de fato, logo após a Segunda Guerra Mundial. Ainda que não exista uma definição de desenvolvimento econômica universalmente aceita. Identificamos na literatura duas correntes de pensamento completamente distintas: uma de inspiração mais teórica, que considera o crescimento como sinônimo de desenvolvimento e, outra, mais voltada para o empirismo, que entende que o crescimento é condição indispensável para o desenvolvimento, mas não é condição suficiente. Essa última, ligada aos teóricos da Cepal, defende o desenvolvimento econômico em pelo menos três dimensões: a do incremento da eficácia do sistema social de produção, a da satisfação de necessidades elementares da população e a da consecução de objetivos a que almejam grupos dominantes de uma sociedade e que competem para utilização de recursos escassos (MORETTO; GIACCHINI, 2003).

O autor Schumpeter, em sua análise, institui desde 0 início, os embasamentos sob as quais atua o mecanismo econômico, que são a propriedade privada, a divisão do trabalho e a livre concorrência. Na Teoria do Desenvolvimento Econômico para aproximar-se do movimento da economia capitalista, este mesmo, difunde a mão de artifício de análise, como um método já presente e citado por outros autores. Trata-se do mecanismo do fluxo circular, uma ideia de criar uma imagem mental, um tipo de protótipo de sistema econômico a partir do qual vai se aprofundando o conhecimento, que foi usado antes por Adam Smith e Karl Marx. Na Riqueza das Nações, na parte em que procura identificar os determinantes do valor 
de troca das mercadorias, Smith refere-se a uma sociedade imaginária, anterior ao capitalismo, a que ele mencionou como o estágio grosseiro e primitivo da sociedade que antecede a acumulação de capital. Já Marx, por sua vez, em O Capital, na explicação do excedente e do processo de acumulação, parte primeiramente de uma economia mercantil simples. Para depois introduzir elementos próprios do modo de produzir capitalista.

$\mathrm{Na}$ economia do fluxo circular segundo Schumpeter, a vida econômica decorre monotonamente, em que cada bem produzido encontra o seu mercado, período após período. Entretanto, não significa concluir que inexista crescimento econômico. Admitem-se aumentos na produtividade, decorrentes de aperfeiçoamentos no processo de trabalho e de mudanças tecnológicas contínuas na função de produção. Contudo, esse alicerce tecnológico já é conhecido, incorporado que foi com o tempo na matriz produtiva da economia.

Os agentes econômicos apegam-se ao estabelecido, e as adaptações às mudanças ocorrem em ambiente familiar e de trajetória previsível. Nessas circunstâncias, de acordo com Schumpeter, mudanças econômicas substanciais não podem ter origem no fluxo circular, pois a reprodução do sistema está vinculada aos negócios realizados em períodos anteriores. A questão para Schumpeter é que as inovações transformadoras não podem ser previstas ex ante. Contudo, esses tipos de inovações, que são originadas no próprio sistema, quando introduzidas na atividade econômica, produzem mudanças que são qualitativamente diferentes daquelas alterações do dia a dia, levando ao rompimento do equilíbrio alcançado no fluxo circular. Assim, a evolução econômica se caracteriza por rupturas e descontinuidades com a situação presente e se devem à introdução de novidades na maneira de o sistema funcionar (COSTA, 2006).

O desenvolvimento leva Schumpeter a procurar estabelecer de onde provêm as inovações, quem as produz e como são inseridas na atividade econômica. Do plano, Schumpeter descarta a hipótese de que elas se originem no âmbito dos desejos e necessidades dos consumidores, embora esses sejam elementos importantes para a adoção e difusão de novas combinações. Todavia, esses atores são passivos em relação à pesquisa e ao desenvolvimento de novos produtos e processos. Apenas os incorporam aos seus hábitos diários. Schumpeter deixa explícito que os meios de produção necessários às novas combinações não estão ociosos, à espera para serem empregados na produção de novos bens. Os recursos para viabilizar as novas combinações já estão disponíveis na sociedade, estando empregados em atividades que compõem o fluxo circular. São as novas maneiras de combiná-los, retirando-os dos locais onde se acham empregados e alocando-os em novas atividades, que se vão produzir, 
então, o que Schumpeter chamou de desenvolvimento econômico (COSTA, 2006. p. 5 e 6$)$.

Segundo Baracho e Fauvrelle (2012), cada sociedade possui um ideal máximo o qual persegue ao longo de sua história. Os norte-americanos, por exemplo, têm na liberdade como seu desenvolvimento. Já os franceses pautam-se na ação pela igualdade. No caso brasileiro, a temática do desenvolvimento é a que possui maior importância. Tanto é que a própria bandeira nacional expõe o lema positivista "Ordem e Progresso" desde a sua proclamação. A procura por melhores formas de concretizar as suas virtualidades e potencialidades é frequente em diversas outras formas de expressão social do país. O prefácio da atual Constituição brasileira aduz que o Estado democrático, por ela instituído, está proposto a garantir o desenvolvimento.

\begin{abstract}
O vocábulo desenvolvimento remete à ideia de transformação, crescimento, progresso; evolução de um status quo ante para uma nova realidade, um estado novo caracterizado por ser qualitativamente, e não apenas quantitativamente, superior ao anterior. Nesse sentido, tal termo se faz presente em diversas áreas do conhecimento humano. Nas ciências biológicas, essa palavra pode estar associada à passagem gradual, protagonizada por um determinado ser vivo, de um estado inferior para um estado mais aperfeiçoado, no qual ele esteja dotado de melhores condições de sobrevivência. Nas ciências exatas, a palavra desenvolvimento pode estar relacionada ao desenrolar natural de uma determinada reação física. Já nas ciências sociais, como é o caso da Economia, o termo desenvolvimento encontra-se, em geral, associado ao desenvolvimento humano; o processo no qual a sociedade humana busca melhor realizar as suas virtualidades e potencialidades (BARACHO; FAUVRELLE, 2012 p. 2).
\end{abstract}

Já faz tempo que o conceito desenvolvimento tornou-se tanto um slogan, como um termo multiparadigmático. Historicamente, o conceito vem sendo construído com base em três visões paradigmáticas: desenvolvimento como crescimento econômico, desenvolvimento como satisfação das necessidades básicas e desenvolvimento como elemento de sustentabilidade socioambiental.

Uma análise desses paradigmas conceituais nos permitirá compreender o que é e por que o desenvolvimento, de que e em direção a que o desenvolvimento nos induz. Tendo em vista que não há nenhum outro conceito no pensamento moderno que tenha influência comparável sobre a forma de pensar e de agir do comportamento humano, tal como compreende-se no conceito de desenvolvimento. 
Figura 01 - As diferentes fases do estudo do desenvolvimento econômico.

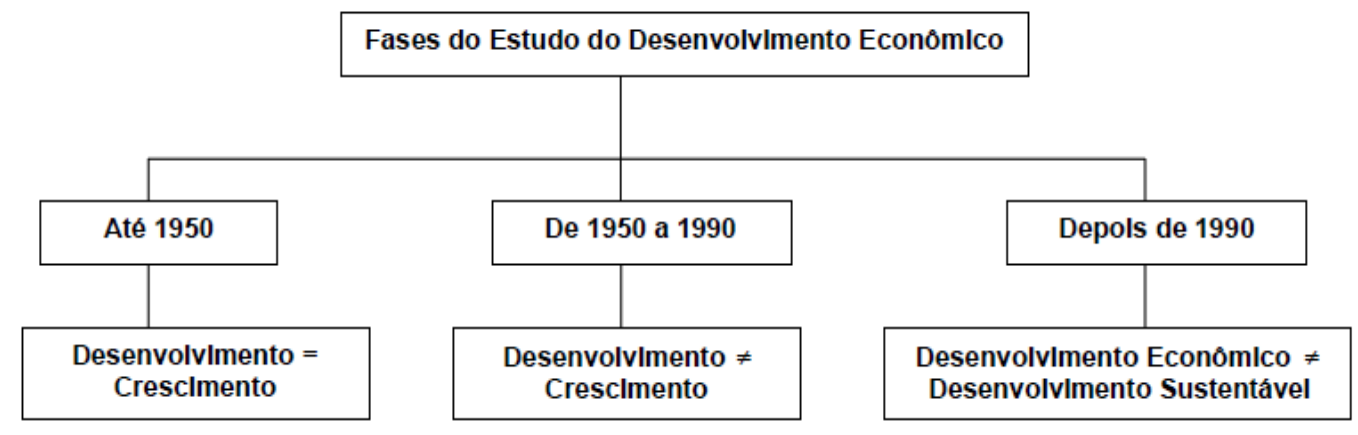

Fonte: MORETTO; GIACCHINI, 2003. p. 4.

Para pensar um pouco sobre essas questões, será exibido as percepções sobre o processo de formação desse conceito na sociedade capitalista. Para tanto, toma-se como referência quatro dimensões de análise: política, econômica, social e ambiental. Todavia, lembramos que tais dimensões não são as únicas que possibilitam esse tipo de compreensão, mas entendemos que são as mais relevantes no atual conjuntura do capitalismo.

Os dois fatores fundamentais a determinar, diretamente, o desenvolvimento econômico é a taxa de acumulação de capital em relação ao produto nacional, e a capacidade de incorporação de progresso técnico à produção. O fator principal a determinar a maior ou menor aceleração do desenvolvimento capitalista é a existência ou não de uma estratégia nacional de desenvolvimento. Na medida em que uma sociedade nacional revela suficiente coesão quando se trata de competir internacionalmente, ela aproveitará melhor os recursos e as instituições de que dispõe para crescer (BRESSER-PEREIRA, 2006).

O crescimento da produtividade de um país depende, diretamente, da acumulação de capital e da incorporação de progresso técnico à produção. Investimento e progresso técnico, por sua vez, dependem, em geral, da qualidade das instituições formais (políticas, leis) e informais (práticas sociais ou usos e costumes) que cada sociedade nacional estiver adotando. Quando uma sociedade é capaz de conformar essas instituições e políticas econômicas para que elas assumam o caráter de uma estratégia nacional de competição internacional, aumenta a probabilidade de que as taxas de desenvolvimento sejam mais altas (BRESSER-PEREIRA, 2006). 
A origem do conceito Desenvolvimento surgiu na biologia, agregado como processo de evolução dos seres vivos para a obtenção de suas potencialidades genéticas. Com Darwin, a palavra desenvolvimento sobreveio a ter uma compreensão de modificação, aspecto como um movimento na direção da forma mais adequada. Um organismo se desenvolve ao alcance que prospera em direção à sua maturação biológica.

Figura 02 - Etimologia da Palavra Desenvolvimento

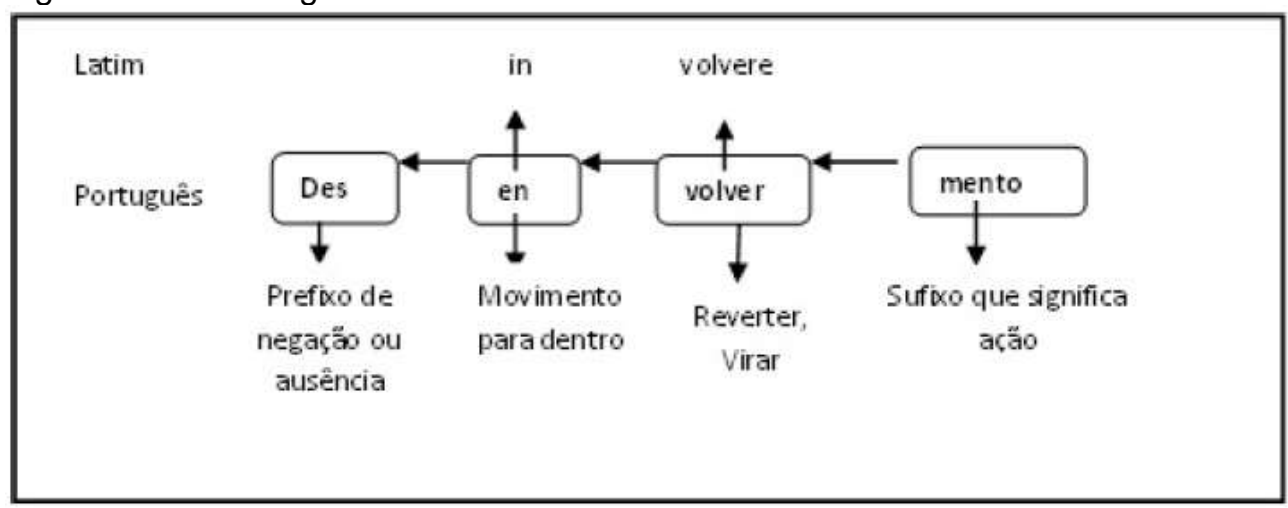

Fonte: SANTOS; et.al 2012 p. 3.

A permuta da biologia para a vida em sociedade ocorreu nas últimas décadas do século XVII e adotou corpo com o darwinismo social. Com ela, pode averiguar que o progresso, a expansão e o crescimento não eram virtualidades inseparáveis, inerentes a todas as sociedades humanas, mas sim características específicas de algumas sociedades ocidentais. Essas sociedades obtiveram 0 status de desenvolvidas, o que faz entender que elas eram capazes de produzir os seus próprios movimentos para a obtenção do seu próprio bem-estar (SANTOS; et.al 2012).

De maneira geral, a inquietação com o desenvolvimento tem suas raízes na ciência econômica. De caráter preliminar, os trabalhos de Adam Smith (1776), Thomas Malthus (1798), David Ricardo (1817) e Karl Marx (1867) exibem o desenvolvimento como um acontecimento extraordinário para a concretização do sistema capitalista. Porém, é na década de 1940 que o desenvolvimento recebe o status de elemento de pesquisa científica com o nascimento da Economia do Desenvolvimento.

Com a consolidação da Economia do Desenvolvimento é estabelecida toda uma estrutura teórica e metodológica para expor e promover o desenvolvimento como algo associado a uma sociedade industrial, urbana e possuidora de riqueza, 
por meio de acúmulo de renda monetária. Esses foram alguns trabalhos iniciais dos economistas famosos da economia, surgiram outros economistas famosos discutindo sobre o desenvolvimento econômico como Furtado, por exemplo.

O desenvolvimento econômico pode ser definido como uma mudança estrutural, ou seja, o desenvolvimento é uma transformação na relação e nas proporções internas do sistema econômico. A sociedade é caracterizada por um conjunto econômico complexo que traduz formas econômicas e sociais diversas. Desse modo, o desenvolvimento econômico ocorre quando o aumento permanente na produtividade média do trabalho se assimila a essa estrutura complexa (QUEIROZ, 2011).

O desenvolvimento é considerado como um resultado do crescimento econômico seguido de melhoria na qualidade de vida de uma sociedade, ou seja, aumento do Produto Interno Bruto e a eficiência na alocação de recursos pelos diversos setores da economia, melhorando o bem-estar econômico e social da população. A redução da pobreza, do desemprego e das desigualdades e aumentos nas condições de saúde, na alimentação, educação e moradia, são considerados melhorias no desenvolvimento (OLIVEIRA, 2002).

O desenvolvimento econômico como crescimento econômico gera aumentos positivos no produto acompanhado por melhorias do nível de vida dos habitantes da cidade e por alterações estruturais na economia. O desenvolvimento deve ser encarado como um processo complexo de mudanças e transformações de ordem econômica, política e é claro, humana e social. O desenvolvimento nada mais é que o crescimento, incrementos positivos no produto e na renda transformado para satisfazer as mais diversificadas necessidades do ser humano, como a saúde, educação, habitação, transporte, alimentação, lazer, etc. (OLIVEIRA, 2002).

A palavra desenvolvimento despacha à ideia de transformação, crescimento, progresso, a evolução de um status quo ante para uma nova realidade, um estado novo caracterizado por ser qualitativamente, e não apenas quantitativamente, superior ao anterior. Nesse sentido, se faz presente em diversas áreas do conhecimento humano e científico.

Nas ciências biológicas, essa palavra pode estar associada à passagem gradual, protagonizada por um determinado ser vivo, de um estado inferior para um estado mais aperfeiçoado, no qual ele esteja dotado de melhores condições de sobrevivência. Já nas ciências exatas, o termo desenvolvimento pode estar 
relacionada ao desenvolver o natural de uma determinada reação física. Com as ciências sociais, como é o caso da Economia, o termo desenvolvimento encontra-se, em geral, associado ao desenvolvimento humano, ou seja, ao processo em que a sociedade humana busca melhor realizar as suas virtualidades e potencialidades (BARACHO; FAUVRELLE, 2012).

Na busca pela melhor satisfação de suas necessidades, os homens se
aglomeram com os seus semelhantes, formando as sociedades. Entretanto,
a produção material - criação de bens e serviços (alimentos, vestimentas,
alojamentos etc.) - é vital à própria existência humana. Nas sociedades, tão
importante quanto a produção é a distribuição. A forma como a sociedade
produz e distribui os bens e serviços que lhe são necessários denomina-se
estrutura econômica. A estrutura econômica é o fundamento sobre o qual se
erguem as demais estruturas de uma sociedade, como a política, a cultura,
a religião e até mesmo a ciência. Assim, em uma comunidade, a vida social
é determinada em última instância2 pela sua estrutura econômica (MARX,
1859). Dessa forma, o desenvolvimento de uma sociedade está
intimamente relacionado ao desenvolvimento de sua economia (BARACHO;
FAUVRELLE, 2012, p.3).

Cada autor tem uma forma de definir desenvolvimento econômico, mas ambos estão conectando desenvolvimento com o bem-estar da população, para haver desenvolvimento em uma sociedade, precisa haver bem-estar social e econômico. No caso do município, para existir desenvolvimento não precisa ser altamente qualificado em tecnologia, mas haver distribuição de renda, melhores condições de saúde, salários melhores, mais educação.

O desenvolvimento não se define apenas na renda que um indivíduo pode ter, como também, nas liberdades que as pessoas desfrutam. Como liberdades políticas, facilidades econômicas, oportunidades socais, garantias e transparência e segurança protetora. $\mathrm{O}$ aumento da capacidade humana ajuda a enriquecer a vida do ser humano. Como acesso à educação básica, saúde, segurança, justiça social, participação política (SEN, 2000).

O problema básico da economia brasileira é a falta de crescimento. O grande desafio é que se obtenham taxas de crescimento do produto de forma mais rápida do que as taxas de incremento populacional". Nesses termos, o crescimento econômico precisa acontecer em ritmo capaz de atender às solicitações das distintas classes sociais, regiões e países. É desta maneira que o desenvolvimento passa a ser entendido como uma resultante do processo de crescimento, cuja maturidade se dá ao atingir o crescimento auto-sustentado, ou seja, talvez alcançar a capacidade de crescer sem fim, de maneira contínua. Em nome do desenvolvimento buscam-se valores crescentes: mais mercadorias, mais anos de vida, mais publicações científicas, mais pessoas com títulos de doutor, dentre vários outros. (OLIVEIRA, 2002, p.41). 
O desenvolvimento econômico é assim um fenômeno histórico, de um lado conexo com o surgimento das nações e a formação dos estados nacionais ou estados nação e, de outro, com o acúmulo de capital e a incorporação de progresso técnico a trabalho e ao próprio capital, que ocorrem sob a coordenação das instituições principalmente de mercados relativamente competitivos. $\mathrm{O}$ desenvolvimento é, portanto um fenômeno relacionado com o surgimento das duas instituições fundamentais do novo sistema capitalista: o estado e os mercados (BRESSER-PEREIRA, 2006).

O desenvolvimento econômico só pode ser compreendido a partir de uma perspectiva histórico-estrutural como também keynesiana. Histórico-estrutural porque nele os três interesses básicos da sociedade, ou seja, a econômica e social, a cultural e a institucional que são interdependentes e transformam dialeticamente. A keynesiana, porque nesse processo não basta avaliar o desenvolvimento econômico pelo lado da oferta, como também é necessário vê-lo pelo lado da demanda.

De acordo com o ponto de vista histórico, o desenvolvimento econômico é um processo de acumulação de capital com incorporação ordenada de progresso técnico que se manifestou historicamente quando a organização da produção social adotou uma forma capitalista ou moderna digamos assim. Apenas a partir desse momento é que passaram a ter vivência histórica de uma classe de trabalhadores assalariados que comercializam sua força de trabalho no mercado, e uma classe de empresários capitalistas que investem e inovam. É a partir daí que o progresso técnico se identifica inicialmente com a Revolução Industrial.

Sendo o momento em que se completa a Revolução Capitalista que passou a acontecer de forma rápida, e o reinvestimento dos lucros com incorporação de tecnologias cada vez mais eficientes e aprimoradas tornando-se uma categoria de sobrevivência dos empresários e de suas empresas.

A hipótese mais do que a conclusão básica é que o desenvolvimento econômico e, mais amplamente, o desenvolvimento humano, só começa a se realizar quando um povo ou um conjunto de povos, no quadro da Revolução Capitalista, se transforma em uma Nação, consegue se dotar de um Estado, e passa a deliberadamente buscar progresso dos seus padrões de vida. De acordo com essa perspectiva, o atuante histórico por nobreza do desenvolvimento econômico é a Nação, ou seja, é a sociedade nacional que, partilhando de um destino comum, 
consegue controlar um território e dotar de um Estado que the sirva de principal instrumento de ação coletiva (BRESSER-PEREIRA, 2008).

A categoria principal a determinar o bom êxito do desenvolvimento econômico é que essa Nação tenha autonomia e coerência satisfatórias por meio do seu Estado, estabelecer uma estratégia nacional de desenvolvimento ou de competição econômica com as demais nações (BRESSER-PEREIRA, 2008).

\begin{abstract}
Histórica ou empiricamente não há caso de verdadeiro desenvolvimento econômico sob categoria colonial. No bojo da onda ideológica neoliberal que sacudiu o mundo desde os anos 1970, pretendeu-se opor o Estado ao mercado no processo do desenvolvimento econômico. Esta oposição, entretanto, não faz sentido. O Estado é a instituição matriz das demais instituições formais de uma sociedade; e nas sociedades modernas, é o instrumento de ação coletiva por excelência da sociedade na consecução de seus objetivos políticos de segurança, liberdade, bem-estar, justiça social e proteção do ambiente. Nesta qualidade, um dos papéis do Estado é o de regular o mecanismo coordenador das economias capitalistas - o mercado. Não faz sentido, portanto, opor Estado a mercado. Ao invés disso, é preciso compreender historicamente as relações entre as duas instituições. Apenas nas duas fases iniciais do desenvolvimento econômico na fase da acumulação original e na da Revolução Industrial o Estado é o agente direto do desenvolvimento econômico. Em certos casos, como aconteceu no Japão, na Rússia e na China, esse papel de agente direto do desenvolvimento econômico torna-se quase absoluto. Terminada está a Revolução Industrial, o Estado gradualmente se retira das atividades produtivas, que não lhe são próprias, transferindo-as para os empresários e as empresas. $\mathrm{Na}$ fase que se segue, a renda per capita e os padrões de vida continuam a aumentar, muitas empresas se transformam em grandes organizações, e, sempre no quadro do desenvolvimento capitalista, formase uma terceira classe além da capitalista e da trabalhadora: a classe profissional ou tecnoburocrática. O Estado, por sua vez, enquanto sistema constitucional-legal ou regime político, se democratiza, ao mesmo tempo em que, enquanto aparelho, cresce fortemente deixando de ser um Estado Liberal para se transformar em um Estado Social (BRESSER-PEREIRA, 2008, p. 4 e 5).
\end{abstract}

\title{
3. CONCLUSÕES
}

O presente trabalho teve como objetivo ilustrar por meio de uma discussão teórica, o conceito de desenvolvimento econômico, com base na visão de BresserPereira e alguns autores. Para isso, foi realizada uma revisão bibliográfica, que fortaleceu a temática da pesquisa. Nesse diapasão, em síntese, pode-se concluir que o desenvolvimento econômico promove a melhoria dos padrões de vida da população em geral. No entanto, não consegue resolver todos os problemas de uma sociedade, principalmente das mais atrasadas e com elites conservadoras. 
Por isso, o desenvolvimento se constitui como um objetivo fundamental que não se opõe aos outros objetivos existentes. O desenvolvimento é, assim, um processo histórico que as sociedades nacionais modernas procuram implantar através de estratégias políticas e econômicas.

Para formular e implementar essas estratégias, as teorias econômicas reducionistas, conhecidas e denominadas de teorias do mercado, são geralmente limitadas, insuficientes e prejudiciais em muitos casos. Constata-se que as teorias histórico-institucionais do desenvolvimento e da macroeconomia, são mais eficientes do que as anteriores.

Nesse sentido, as teorias pragmáticas, que orientem a ação prática e as teorias que consideram as estruturas econômicas e as instituições, a sociedade e a política, o mercado e o poder são muito mais eficientes do que as reducionistas ou simplesmente pró-mercado. Isso, dito, quando se pensa efetivamente o desenvolvimento ampla, latu sensu da sociedade.

\section{REFERÊNCIAS}

BARACHO, Hertha Urquiza; FAUVRELLE, Thiago A. Desenvolvimento Econômico: O Conceito Histórico na Constituição Brasileira. Texto presente na bandeira nacional desde a sua adoção em 1889. Resume o mote do positivismo "L'amour pour principe, l'ordre pour base et le progrès pour but", ideologia largamente difundida quando da proclamação da república brasileira. 2012.

BRESSER-PEREIRA, Luiz Carlos. Conceito Histórico de Desenvolvimento Econômico. Trabalho originalmente preparado para curso de desenvolvimento econômico na Fundação Getúlio Vargas. Versão de 2 de março de 2006.

BRESSER-PEREIRA, Luiz Carlos. Desenvolvimento Econômico e Revolução Capitalista. Escola de Economia de São Paulo da Fundação Getúlio Vargas FGVEESP. Texto para discussão 170. São Paulo, setembro de 2008.

COSTA, Achyles Barcelos da. O desenvolvimento econômico na visão de Joseph Schumpeter. Universidade do Vale do Rio dos Sinos Instituto Humanitas Unisinos. São Leopoldo RS Brasil, 2006.

MORETTO, Cleide Fátima; GIACCHINI, Jussara. Do surgimento da Teoria Do Desenvolvimento a Concepção de Sustentabilidade: Velhos e Novos enfoques rumo ao Desenvolvimento Sustentável. MESA 1: Teoria Econômica e Meio Ambiente: meio ambiente na teoria econômica. São Paulo, 2003. 
OLIVEIRA, Gilson Batista. Uma discussão sobre o desenvolvimento. Revista da FAE, Curitiba, v.5, n.2. 2002.

QUEIROZ, Júlia Melo. Desenvolvimento Econômico, inovação e meio ambiente: a busca por uma convergência no debate. Cadernos do Desenvolvimento, Rio de Janeiro, v. 6, n. 9. 2011.

SANTOS, Elinaldo Leal; et.al. Desenvolvimento: Um Conceito Multidimensional. Revista Eletrônica do Mestrado em Desenvolvimento Regional da Universidade do Contestado - DRd - Desenvolvimento Regional em debate Ano 2, n. 1, jul. 2012.

SEN, Amartya Kumar. Desenvolvimento como liberdade. Título Original:

Development as freedom.Tradução Laura Teixeira Motta; Revisão técnica Ricardo Doninelli. São Paulo: Companhia de Letra, 2000. 